\title{
KINSHIP IN CONTEMPORARY JAPANESE SOCIETY : AN OVERVIEW
}

\author{
Lopamudra Malek ${ }^{1}$ \\ Md. Saifullah Akon ${ }^{2}$
}

\begin{abstract}
The paper seeks to analyse the salient features of the kinship structure in Japan and how it plays it is significant role to form the traditional Japanese values. The paper also tries to analyse the changing nature of the kinship system in contemporary Japanese society from its traditional family (IE) system. The paper follows the qualitative method of research where the data has been collected from both academic and non-academic sources. By analysing the kinship structure of different periods in Japan, the paper finds that during the IE family system of the Tokugawa period, Japan gives less weight to kinship relations than other Asian countries. The feeling on son, either related to blood or adopted, marks the major distinction with other societies to find out the kin and non-kin. Following the IE system, the paper finds another two major events behind the weaken kinship structure in Japan: the emergence of koseki since the Meiji restoration and the rise of corporate culture during the contemporary period.
\end{abstract}

Keywords: kinship, IE family, Dozuku, Koseki system, corporate culture.

\section{Introduction}

In the social web of societies, kinship was considered as an important component to define the biological relationship. It determines one's relatives and their relationship with them ("Types of Kinship and Descent Systems; Its Advantages and Disadvantages," 2015) who are being connected through descent or marriage. It is the basis for establishing social groups (Hidasi, 2014). The kinship system binds people and ensures its position in society. To live in society, family members get various support from their close and related relatives. In other words, the kinship system gives perfection to a person in society in many ways.

1 Lopamudra Malek, PhD is Assistant Professor, Department of Japanese Studies, University of Dhaka, Bangladesh. Email: lopamudra.jsc@du.ac.bd

2 Md. Saifullah Akon is Lecturer, Department of Japanese Studies, University of Dhaka, Bangladesh. Email: msakon72@gmail.com

Social Science Review [The Dhaka University Studies, Part-D], Vol. 37, No. 2, December 2020 
In society, kinship relationship is determined by two processes: blood relations (consanguineal kinship) and marriage (affinal kinship) (Faridi, 2019). Differences in kinship relations and its rules and patterns are observed in different societies around the world. Like other societies of the world, kinship has a great influence on Japanese society, particularly in terms of transmitting status and inheritance to the new generation. In Japan, kinship was considered as the stem of the family. As a discourse of Japanese culture, $I E$ remains at the heart of Japanese society which includes all people and things surrounded by a particular household. This $I E$ family system has often been considered not only as a symbol of Japan (Kuwayama, 2001), it has a foundation deep down which is spiritual (Yanagita, 1997). In this $I E$ system, the headship passed from the father to the eldest son and if there is no biological son then a son might be adopted (Kuwayama, 2001) to continue the family system and maintain the group.

In Japan, however, the importance of the $I E$ system varies from region to region. For example, in rural areas, the effect of the IE system is more pronounced than in cities in Japan. To the people of rural areas, the value of collectivity is more than individuality. Even, the ideology of 'we', which occupies the individual minds, has deep meaning to the member of the rural family than the idea of 'I' in the urban family (Kuwayama, 2001).

A transition of kin roles from its traditional IE system to the Koseki through Meiji restoration is also observed in Japanese society. Earlier, kin roles were limited within the family. However, in the post-war period, there was a marked change in kinship relations in Japan, which was rooted in structural changes in the family system. With economic development and urbanization, extended families disintegrated, and nuclear families sprang up, causes the diminished role of the head of the family in the IE or Koseki system. As a result, kinship relations in Japan are weakening gradually which is completely different from other Asian countries.

In contemporary corporate societies in Japan, kinship has also received less importance. Although the family system in Japan changed radically in the aftermath of WWII, it can be seen that root of the current Japanese business establishment is the $I E$ system of the Tokugawa period. As a result, it is still followed in managing these family businesses. As the head of the $I E$ family system, the company head has taken the responsibility for the wellbeing of his employees. Here the company's employees and their families are given more priority than the kinship relationship, which reflects their traditional system. 
However, the paper has four major objectives: 1) to give a historical overview of Japanese kinship structure from significant pieces of literature; 2) to analyse the conception of the $I E$ family system in Japanese society; 3 ) to describe the nature of kinship in Japan, particularly from $I E$ family system to present Japanese society; and 4) to demonstrate the changing patterns and values of kinship in the contemporary Japanese corporate culture.

\section{Methodology}

The study has been conducted mainly followed by the qualitative method approach, which provides a complete textual description of the kinship structure in Japan. It also enables us to find out the major characteristics of Japanese kinship and how it works in society. To review the literature, data has been collected using secondary literature tools - both academic and non-academic sources. Books and journals were explored as academic sources while newspapers, magazines, blogs, and websites were considered as nonacademic sources.

After reviewing the literature, the study first tries to identify the origin of kinship terminology in Japanese society and how it characterizes society. As mentioned earlier this paper has four sections. The first section presents a brief historical overview of the Japanese kinship structure, second section analyses the formation of the $I E$ family system. The third section discusses nature of kinship structure in Japanese society focusing on the existence of kinship in the contemporary $I E$ family system and how it works in the present day and finally, the last section analyses the changing pattern of kinship structure in the Japanese corporate culture. All these mentioned parts are evaluated through critical analysis of the related and relevant documents following the qualitative method.

\section{Literature Review}

Different literatures help us to understand the major characteristics of kinship structure in Japanese society and how it plays a significant role to form the traditional Japanese values. In our paper, we tried to show the formation of kinship in the traditional Japanese society and current Japanese society as well. The literature that we discussed below also helped us to identify the research gap, particularly the shifting values of kinship structure in the contemporary Japanese corporate culture. 
To describe the traditional Japanese family system, British sociologists Ronald Dore in his book 'City Life in Japan (1958)' argued that, family (IE) is the primary entity of greater importance than any other, and the individual is considered as the representative of that particular family. According to Dore, though the $I E$ system was revised in the post-WWII since it was first instituted by the Civil Code of 1898, the impact of the $I E$ system did not lessen and continued its implications throughout Japanese society in layers. This was also mentioned by Ezra Vogel in his book Japan's New Middle Class (1963), where he pointed out the importance of $I E$ to explain oneself to be Japanese. In his classic piece of work, he also described that, though a rising middle-class society since the mid1950s had shaken the IE system, it did not completely bring down the IE system and it remains as the heart of the Japanese family.

Kunio Yanagita in her Time and Agricultural Policy (1997) also described the inheritance of property in the IE family system. According to Yanagita, in terms of inheritance, IE property passed from father to the eldest son while other noninheriting children only get economic support. Besides, describing the meaning of Japanese words parents and children as oya and $k o$, which originally means 'parent-status' and 'child-status', she focuses that during the IE system, people without biological connectivity also can be involved within this relationship. To define the nature of kinship, this terminology was also described in Argia's work Dozoku to shinzoku (1947). In this classic, Argia described two Japanese terms, oyako and itoko, meaning parent-child relationship and cousinship respectively (Befu, 1963). Here oyako represents the dozoku (patrilineal families) and itoko represents the kindred.

The importance of kinship in traditional Japanese society is further understood through Hiroko M. Maeda's article Name Changes and Kinship Ideology in Japan (2010). In his article, Maeda shows the tendency to change surnames in Japan to understand the peculiar Japanese culture. According to Maeda, more than 300,000 surnames are used in Japanese family which brings significant social values. Usually, Japanese women change their surname after their marriage and take their husband's family name, which is unusual to other Asian cultures, but it has a connectivity with Indian Hindu community. Such frequent name change in the Japanese family system ultimately reflects the flexibility of the kinship system in Japan (Maeda, 2010). 
But the kinship system is being observed as different in rural and urban areas in Japan. Comparing the rural and urban families, Koyama in his book Gendai Kazoku no Kenkyu (A Study of the Modern Family) (1962) shows the different attitudes toward their families from a traditional perspective. He shows that, regarding the issue of caring for the parents, the role of the elder son, and adoption, rural people follow traditional values and have the values to respect their family tie., On the other hand, urban people show less respect and perform fewer duties toward their families as well as their parents (Koyama, 1962).

On the other hand, Chie Nakane in her book Japanese Society (1970) shows an alternative nature of kinship in Japanese society. According to social anthropologist Miss Nakane, kinship ties in Japan are weakening due to the importance of 'frame' culture rather than 'attribute'. Comparing to other societies i.e., England and America, she shows that Japan gives fewer status to kinship relations than others. Miss Nakane also shows that kinship, as a basic human attachment became compensated due to the emergence of the corporate group. Nakane also pointed out that, in rural Japan, people give more importance to their neighbours rather than relatives and these people think that they can carry their life without cousins but not without their neighbours. Such an idea shows the true picture of the nature of Japanese kinship, where the family is built on the principle of the frame, and in this frame 'corporate group' slowly eroding kinship ties in Japan.

\section{Historical Background of Japanese Kinship Structure}

Anthropologist Ashley Crossman defined kinship as 'the most universal and basic of all human relationships and is based on ties of blood, marriage, and adoption.' Theoretically, Kinship is one of the core consolidating doctrines of society. This fundamental association creates a relationship between the individual and the clutch. It is based on two constituents. Though some sociologists and anthropologists count the third one - the social ties as well, but the most significant one is 1 . Consanguineal and 2. Affinal kinship structure

1. Consanguineal: People who are directly connected through blood relations, like, mother-son-daughter or father-son -daughter, so on and so forth are in the consanguineal group. This is the most basic and primary kinship among blood relations by means of parents and siblings. 
2. Affinal: This relationship is based on marriage among those who do not obtain blood connection, like husband and wife. Affinal is also included in the fundamental kinship definition (Ashley, 2020).

According to Judit Higasi, an anthropologist labels one individual as 'Ego' to proceed with the kinship discussion and he mentioned that other person related to him in blood connection knot or not, are stated as kinship. In the unilineal descent principle, the fundamental forms are patrilineal and matrilineal descents. The people who follow the unilineal descent principle, they reverence both the fundamental sides. There are another two descent patterns namely ambilineal and bilateral descent which meant they respects all the ancestors from paternal and maternal sides. Japan is in the righteous assortment of ambilineal descent principle and bilateral descent principle at the same time. In the ambilineal descent principle, people choose only one side among the paternal and maternal sides as his or her descent trace and follow that. In the case of bilateral descent patterns, they count all the genetic descendants regardless of their gender and this principle is slightly male-biased (Higashi, 2014). Japan follows both the patterns simultaneously focusing on the slightly male-biased category.

There are six extensively occurring basic forms of kinship. Those are 1.Sudanese 2. Hawaiian 3. Eskimo 4. Iroquois 5. Omaha 6. Crow. The Japanese kinship pattern lays in the eskimo type group terminology. The Eskimo structure is patented with the bilateral emphasis which meant there is no existence of discrepancy between patrilineal and matrilineal relatives. Along with that, there is an acknowledgment of differences in kinship structure as relatives- relations, which are defined by how to distance the relation. Another aspect of Eskimo term is, it is more likely the nuclear family structure category. It emphasizes on the nuclear family structure more than a family structure with extended and greater kinship group (Schwimmer, 2001). Following Befu's work, Japan is the country where two systems of ancestry- the unilineal (in this case, patrilineal) and the bilateral, function together parallel inside their society (Befu, 1963: 1329).

The first and foremost foundation is the formation of the $I E$ system in the $13^{\text {th }}$ century onward following the 'Hagakure' (はがくれ) path which is the way of the samurai class and that created the necessity of kinship arrangement inside the society. Before that also, in the Nara, Heian periods, people used to maintain some extent of brotherhood among their society to keep the harmony untouched and undisturbed. In medieval Japan $\left(12^{\text {th }}\right.$ to $\left.15^{\text {th }}\right)$ warrior kinship ties were 
established more firmly and decisively. Apart from the theoretical realm of kinship analysis, in those days the existence of military kinship, a non-biological kinship which could be referred to as milk kinship started to be in practice (Gouge, 2017:3). The samurai culture has strengthened the kinship knot and the rest of the society followed that path unquestionably. Hierarchy was the key element for this tie.

Filial piety was the high and distinguished unwritten law of Japanese kinship. It was adopted from China along with Chinese Buddhism, Confucian ethics, and Chinese culture in the sixth and seventh century AD and that dominated the clan culture undoubtedly. Japan as a vertical society has nurtured this hierarchy with filial piety and continued to knot the tie of kinship authoritatively with it. Though the hierarchy was dependent on sexism as the prior concern of the whole thing was to maintain a proper group with a proper group leader which was based on male-biased kindred (Benedict, 1946:53).

The Meiji government had institutionalized the Japanese family structure after the Meiji restoration (Yamane \& Nonoyama, 1967). Ezra F. Vogel did extensive research from 1958 to 1960 on the Japanese family system and in his work, he mentioned that even in those days also, the kinship system was mainly based on family inheritance which is in Japanese term- Dozoku (どぞく). The elder son was supposed to stay with his family and take care of the family possessions and elderly parents when the second and third ones were free from these responsibilities as well as family inheritances partially (Vogel, 1963). Here it could be determined with the remark following their history of kinship that Japan is a steamed kindred society with the inheritance of slightly biased patriarchy structure and having a nuclear family structure underlying. The patterns and existence of nuclear family structures were in practice in Tokugawa Japan (Hareven, 1991).

After completion for World War II, large number of people migrated from rural agricultural areas to large company-oriented cities. From mid 1950s Osaka, Tokyo and Nagoya started to be populated with the migrant community. In 1947 the Meiji Civil Code reformed from the Meiji Civil Code (Law-9) and adopted the conception of conjugal life and equal inheritance among the children. Probably that reinforced and touched the root of the $I E$ conception predominated in Japanese society (Kato, 2013). But historically, along with the other societies, Japan correspondingly has a multifaceted and complex structure of kinship culture. 


\section{'Kinship' in Japanese Terminology}

Perceived from a broader perspective, Japan is a vertical society that always has an $O y a-k o$ (親一古) relationship inside their society. Factually, this $O y a-k o$ (親 -古) relationship carried on for a long period but now in this postmodern era, we could find those fading away gradually with social, economic changes and with the changing values.

According to Nakane, Japan's kinship terminology could be analysed with a sharp demarcation of Uchi (家) and Soto (外) concept. Japanese people always had and have a strong belief in this notion. Soto (外) means outside and Uchi (家) means inside. Outside, for instance, inside one fictitious company, they maintain a senior-junior (Senpai-kohai) (先輩一後輩) relationship. They use some specific terms to address them and a feeling of brotherhood flows silently among the coworkers which could be addressed as soto (外) from outside, but the employees of that specific company find that as uchi (家), or it could be said a big family under an umbrella. The employees, who have joined the company in the same year and those who have passed out their universities in the same year are roughly colleagues and they address each other with using san after their names and the term is Doryo (度量). This Doryo (度量) could be recognized with some terms and conditions abruptly. For example - Uchidasan (a fictitious name). But those who are seniors addressed with their company positions, such as, the man who is the section in charge, he or she might be addressed as Buchyo (部長), the manager should be addressed as Kachyo (課長) and president or chairman of the company or managing director should be addressed as Syacho (社長) (Nakane, 1970). These designations are all positional names which meant unit chief, manager and chairman/president. This practice could be seen in case of company. Inside their company everyone is under the Uchi platform and all the other companies are addressed as Soto. The segregation between 'us' verses 'they' are extremely prominent in Japan which erodes kinship brotherhood.

In their Family life, Japanese people use the terms to address the people inside their household have a great similarity as we people do. For example, they use all these terms as; elder brother - Anisan (兄さん), elder sister- Anesan (姉さん), uncle - Ojisan (おじさん), aunt- obasan（おばさん）, grandfather as Ojiisan、（おじ いさん) and grandmother as obaasan (おばあさん). Their children call their parents as Chichi (父) (Father) and Haha (母) (mother) but when they are supposed to talk about other person's parents, they will address them as Otosan 
(お父さん and Okasan (お母さん). The wives are addressed as okusan (奥さ ん) in Japan (Minna no nihongo). We do not prefer to call our elders by name and so they do.

Suzuki Takao in his book has described today's Japanese kinship terms from sociolinguistic perspectives and shared it in two divisions (Suzuki, 1978: 142).

1. Egocentric: It is from the first person's position. For referring a specific family member, they place the speaker in the pivotal point and address accordingly. For example, Anisan, chotto tetsudatte（兄さん、ちょっと手 伝って) (Brother, please help me a bit).

2. Allocentric: It is an empathetic identification. This is currently regarded as the utmost favourable technique of addressing a member of a Japanese family. Often, they use the association with the youngest child's perspective. The person speaking transforms his or her identity with the youngest child mentally and position and addresses people from his or her position. For example, the wife addresses the husband calling papa identifying herself with an empathetic identification with the child. For example, the mother asking- What time is it now, father? Papa, ima nanji? (今、何時) (Suzuki, 1978: 142). Here, the mother is mentally identifying herself with the child and calling her husband from the position of her child. This is a way to teach the child about what he or she should call their father.

These are the basic kinship terminologies Japanese people often use inside their households and in their workplaces as well. They prefer to maintain their hierarchy inside the house and their community and society and maintain the filial Piety through these sociolinguistic terms. One specific part should be pointed out that they prefer not to call people by their names only which Americans and Europeans often do. Japanese people priorities their basic bonding, their relations stand first and they always prefer and endorse the group, not the individual (Krakow, 2014).

\section{The conception of the $I E$ (家) system in Japanese society}

Family is the initial and principal social organization of human beings as a social instinctive. Household is its structure and that could be described as IE in Japanese social concept. This is the initial community concept that renders its 
shadow in every aspect of an individual's life. It is a well-established factor that we start our socialization from our home, then school and finally when we start to work, various social interaction come to our way. Whether the person joins a company or business, the basic conception of patriarchal Japan will remain as same as the household concept persisted in layers but of course in new apparel (Nakane, 1970). IE is a conception that refers to the Japanese household system. This demarcates the structure of Japanese society from before the Edo period through the early modern to post-war economic boom period. Some anthropologists and sociologists believe that in this $21^{\text {st }}$ century, the IE system had faded away from society and it has only remained in the marriage ceremonies and funerals, but some researchers differ to that (Sakata, 2013). It could be said that the conception of $I E$ exists in Japan even nowadays, but it has modified its historical structure which is obvious.

The IE concept has governed Japanese people's minds, values, kinship, and society for many years. The definition of $I E$ formation according to Satoshi Sakata is that "the $I E$ is a social framework designed to continue over generations, under which an inherent family homestead, family name, and business are passed on from father to the eldest son along a paternal line that can stretch for generations' (Sakata, 2013). This remark could be taken as the most relevant definition of $I E$ classification. Regarding this $I E$ culture, American and European sociologists done rigorous research on this specific topic and it was in attendance for a long while. Sakata described this $I E$ system in two specific categories and following him it was the pre-IE system and post IE system. In the pre-IE system, it was like modern days when equality was present in the society. Nara, Heian, and Kamakura these ages were mostly pre-IE societies. From the $13^{\text {th }}$ century onward, with the establishment of the samurai class, this $I E$ system evolved with kinship having filial piety in the midpoint. The post-war civil society could be addressed as a post-IE society (Sakata, 2013).

Historically, during the Heian period, UJI system was established for empowering each of the families in terms of prospering property and power. In those days women have their rights on the family property. The kinship portents have started after the historical Mongol Invasion in 1274 to 1281. Before that, women had some freedom but that was also to make sure of men's power but after the establishment of $I E$ system, women lose their control on several things like property, inheritance of power practice and thus one single line patriarch system 
established to command men's wife, siblings, and children. Finally, the IE system started at the beginning of the $13^{\text {th }}$ Century along with the samurai culture under a single heir. But this system emphasized on the samurai families prior. It must be mentioned that in terms of the firm families, they emphasized on marital conjugal happiness and family happiness more than making it patrilineal. After those ages, at the time of Meiji restoration, the government set a national standard of civil law. In this modern post-war era, the constitution emphasizes equality but in reality, the conception of the $I E$ system and its hierarchy is predominated in Japanese society and mindset and that notion is not abolished to till date. Then industrialization appeared with modernization and played a vital role and as an essential fact in Japan, the people were about to get more accustomed to the nuclear family knot. The dilemma of those days was beautifully described in Nakane's analysis (Nakane, 1970).

In reality, from the very beginning, the human race has realized the expediency of society. Perceptual dissimilarities created groups and the same thinkers' and the social responsibilities and urge stimulated villages. In the case of Japanese society, the ideology of Japanese group construction can be seen as depicted in the household structure. Following Chie Nakane, the author of the book namely "Japanese society (Tateshakai o Ningen Kankei)"- Japanese society could be defined with attribute and frame. Attribute means individuals being a member of any exact descent group. But attribute may be obtained not by birth but by someone's accomplishment as well. Discussing from the context of a company, a person holding the post of managing director is his attribute, but a member of the "X" company refers to his frame. In the same way, "Professors", "staff", "students" are attributes, while "people of "Y" university is a frame. The concept of Frame came from the Japanese concept (場) which means place or location. It is difficult to explain this concept in other languages. Some people working and living in the same locality and situation with more or less undistinguishable notions could be defined as (場) frame. In Japan, they prefer frames rather than an attribute. So, they preferred household not just as a home but a group of people under one 'ba' (場) or 'wa' (場) which is a frame. In any society, folks are assembled into social echelons based on attributes and frame. But the pattern of social groups based on encoded frames relics' uniqueness of Japanese social structure nurtured filial piety as the major structure of Japanese civilization (Nakane, 1970). 
A group or a household forms based on shared aims. It has a sturdy logic of exclusiveness based on homogeneity. To strengthen this frame furthermore, there is a necessity to create a strong feeling of hierarchy and feelings of belongingness. Nakane's frame - attribute theory is perfectly applicable to Japanese society as analysed above. Hypothetically it could be done in two ways in the Japanese group criterion which initially was based on the family system and then extended. In their patrilineal society, they have two specific components to strengthen that family and kinship tie and with industrialization, the kinship tie has extended its expanse from a single household to a company community. The harmony which they had started with a single household, has protracted to a bigger family- company.

1. Feelings of Oneness: Disparity of Attributes is a rational thing. People coming from different attributes can be led to feel that they are from the same union by stressing the group consciousness-"us" against "them". With the help of nurturing rivalry against different similar groups, the feelings like "members of the same commodity" gets stronger. The power of collectivism not only enters their life, very considerably it changes their ideas and ways of thoughts as well. Thus, the individual autonomy gradually gets decreased and after that, the household or the company or organization uses them with great convenience. Some individuals create a household and those specific households' senses the feeling of oneness inside the house or feel like a group outside the house. That belongingness helps him to protect the tie he possesses. But the knot of that tie changes slightly according to the time change. Nowadays, that household feelings in which $I E$ was rooted as kinship have changed accordingly and now at the time of post modernization, this conception has switched from household to company peer-feelings, but the root remains the same and unchanged (Nakane, 1970:90).

In modern times, filial piety is the reason behindhand for Japanese people's strong kinship connotation inside the company or any workplace which they had in practice from a long ago. They feel a thousand times comfortable discussing their problems, love-life, stresses with their colleagues rather than their siblings or friends as they used to feel inside the household group criterion. The conception of kinship has deliberately changed its structure to cope up with the social changes that came with 
modernization but the basic remained unbothered as usual. Continual human contact makes this achievable. Eventually, the company take the responsibility of the entire employee as the head of the hierarchical family and take care of even its employee's families and covered huge kindred steam under one group consciousness. In this newly established kinship concept, Japanese society got highly accustomed to it and incarnating it consciously and subconsciously. The company comforts its employees by reassuring that the company is always there for their families as a father figure as it persisted in their household perception (Nakane, 1970: 9-11).

2. The inner association which knots the individuals in the group as a household or IE: The conception of we versus they and us verse them ignite the household or the company to progress their prosperity in terms of wealth, status, and publicity. In previous days, they focused on and emphasized on group building and its development, and nowadays they concentrate on the same conception in their companies which strengthens the knot of kinship inside the company as it was in a household in a smaller percept. To establish that specific filial piety inside the company, they provide housing provision for the employees. The provision of housing facilities is incredibly common in Japanese companies. This company houses are built in a single area where all the employees could live together as a family under one umbrella. Thus, the wives of these employees also come closer, become friends, and for being in the same company, they have the opportunity to be well informed about their husband's activities in the workplace or about extra-marital affairs from each other. Thus, they ensure kinship in a broader aspect as it was perceived long back in Japan (Nakane, 1970). The basic of society is its changes according to time and need of the respective civilization. Japan is no different from that. Even more, Japan is aware of when to change and when to not.

\section{Nature of Kinship Structure in Japan}

Kinship structure in the IE family system

Since the Tokugawa period in Japan, the $I E$ system became the basic unit in Japanese society, and the other features of the Japanese social system cantered on 
this system. In this traditional family system, kinship relations were cantered on the family, where everything was determined by the head of the family. It should be noted that, in the $I E$ family system, the authority of the household head was not limited to the woman and children, but also over the siblings of the household head (Ravina, 2017). Even when the eldest son became the head of the family, the rest of the family members, including his younger brothers and sisters obey him. Because the sister remained in the family until she gets married elsewhere. Even if the younger son wants to get married, he often has to take the elder brother's permission as the new bride will enter the elder brother's household (Ravina, 2017). It ultimately focuses on the non-particle inheritance practice in the $I E$ family system.

During the $I E$ system, kinship was based on upper-class family patterns ("Culture of Japan," n.d.). The major differences between kinship in the traditional family system to the rest of Asia or particularly from South Asia are the feeling of the son (either related to blood or adopted). In South Asia, without blood relations, no strong feeling is seen toward the son who is adopted. This is a distinction between kin and non-kin relations (Befu, 1971) between South Asia and Japanese society as well. Traditionally, kinship does not focus only on heterosexual reproduction but many other ways i.e., adopted children or parents, neighbours, workers, or merchant partners. Especially childless families adopt children from other families to ensure their family inheritance. Sometimes, fictive kinship relationships are seen to observe in the $I E$ family system in the case of a merchant. In such relations, the members of the merchant group maintain relations with the head of the $I E$ and participate in several familial programs.

A complex system exists in the traditional Japanese IE family system, where several generations live together, following the strict family rules. But in that system, if a child lives separately after marriage, he is no longer considered a member of that family. Rather, servants and clerks are incorporated as the members of the household (Nakane, 1970). However, all these characteristics ultimately make the $I E$ family system is more economic organization and creates a corporate group rather than a blood-related kinship group, which is different from South Asian culture.

\section{Status of Kinship in Present Japanese Society}

After the Second World War, the social system of Japan underwent great changes. The new constitution was written by the allied powers. Due to the new 
constitution, Japanese women, once neglected, began to play a bigger role in the country's economic development. A western styled social system became to spread all over the country.

The wave of this new social system also affects the family system in Japan. The $I E$ family system of the Tokugawa period was also very effective even in the Meiji era. But changes also took place in the family structure since the Meiji restoration. The Meiji government instituted Koseki system where all family members are required to register. They also set some legal norms and standards for family formation. Besides, it sets out clear rules about who the family members will be, patterns of inheritance, the marriage, and the head of the family's right to the property ("Culture of Japan," n.d.).

In the post-war period, the Japanese family system began to change radically where patriarchal authority became reduced, joint families disintegrated and the nuclear family began to take shape. The number of nuclear families has increased significantly, especially in urban areas consisting of parents and their children ("Culture of Japan," n.d.). In some cases, extended families are also seen where their elderly parents live but that number is very low. Nuclear families are also in the process of breaking up. In contemporary Japan, the trend to get married is declining, and the Japanese are less willing to have children even if they get married. The number of unmarried and single parents is also increasing in Japan. As a result, the kinship relationship is slowly weakening and the kin group is unable to play a major role in people's lives ("Culture of Japan," n.d.).

The new constitution also amends family law and emphasizes cooperation in the family formation where husband and wife will maintain equal rights. According to the constitution, the family act must be grounded on 'individual dignity and the essential equality of the sexes' (Ravina, 2017). The younger member of the family as well as the female members enjoys the upper status, sometimes equal to others, in the present Japanese society. In this changed social system, on the one hand, the respect of the relatively younger member of the family has increased, on the other hand, the older people in the family are most in a disadvantaged position ("Japan Is Fighting Back against Loneliness among the Elderly," 2019). Especially, when this senior member of the family gradually loses income or retires, he has to go through the most hardships, which completely different from the previous $I E$ family system. 
More surprising is that most young people are not interested in caring for older people. That is why in many cases the elderly has to live alone or even if he lives with someone in his family, they live with hardship due to the reluctant behaviour of the members. As a result, a downturn is being observed in the present Japanese social system. The most worrying thing is the declining birth rate in Japan. As a result, the boundaries of human kinship are naturally getting smaller. It is becoming harder to find heirs to continue families and family business, which has direct impacts on kinship relations.

\section{Changing Pattern of Kinship in Corporate Japanese Culture}

The corporate culture that currently exists in Japan is essentially an extended version of the pre-war Japanese $I E$ system. As can be seen, in the traditional $I E$ system, families were considered as a corporate economic unit ("JapaneseKinship," n.d.), which was patriarchal. Besides, the head of the family was entrusted with the responsibility of taking care of the well-being of his family members. Since then, the household has been considered as the basic unit of Japanese society, which is also observed in the present Japanese corporate culture.

The origin of most businesses or large firms in modern Japan dates back to the Tokugawa period. The Zaibatsu, in particular, have been adopting family ownership since pre-industrial times, i.e., the Tokugawa period (Morikawa, 1992). The traditional $I E$ system has played the most effective role in sustaining this family business or in sustaining this family ownership, focusing on the necessity of continuing $I E$ in Japanese society (Nakane, 1967). Adoption became the norm in Japan, mainly because of the need to maintain continuity. Childless families would adopt children from their nearby families to ensure their inheritance. Mercantile families in particular, who were childless or without male heirs, recruited heirs as a strategy to sustain their family business. As a result, the kinship relationship changed and adopted heirs became more prominent in Japanese society than blood relatives. Since most of Japan's current business has been established in continuity since the Tokugawa period, the influence of the $I E$ system has been observed in the contemporary corporate culture of Japan.

One of the major characteristics of corporate culture in Japan is that groups are given more prominence than individual interests. Following the Confucianism ideology, the Japanese people maintain a social hierarchy where the group is most sacred to them. But other countries, such as the United States, usually 
follow a structured individualism system in the workplace and their main interests are how to further develop one's career (Sara, 2018). In Japan, male supremacy is noticeable in all sectors of society. Such dominance can also be found in Japan's industrial and corporate sector, where men still play a central role. Japanese society still ranks individuals and their families based on the employer's reputation, job, and prospects ("The Company in Japanese Business Culture." n.d.).

Employees in Japanese companies usually serve the same company for a lifetime and generally, they do not switch their jobs. This long-term relationship builds a strong tie between the company, the manager, and his employees. This good connection forms a close community apart from their own family where employees share their leisure time, family, and social events. In this newly established corporate society, families are cantered on a company. Sometimes the relationship between the co-workers of the company is so good that it is seen to maintain a kind of hierarchy like family. Such corporate culture in Japan has created a kind of corporate family that is more connected and influential than blood ties ("The Company in Japanese Business Culture." n.d.).

The kinship relationship development is based on the idea of 'attributes', the Japanese consciously downplayed their siblings, establishing a kind of 'frame' culture in Japan. Usually, the Japanese wealthy brothers do not support their poor brothers or sisters. Based on the 'frame', according to Nakane (1970), corporate groups give less importance to the siblings than their business partners. Even, married siblings, who live in another household, are considered as outsides. Kin relationships are limited to certain events such as seasonal greetings, participation in a wedding or death anniversary, and some financial support in emergency cases. Apart from this, there is no significant role of nepotism in Japanese corporate culture.

Another major reason why blood related kinship ties have become less important in contemporary Japanese culture is that family customs have moved to the marginal line (Goldfarb, 2016). The reluctance of young people to marry has dealt a major blow to traditional family system in Japan. This has had a negative impact on the demographic situation in Japan. It is seen that due to reluctance towards marriage, the birth rate in Japan is low on the one hand and on the other hand most couples do not want to have more children even if they get married. Due to this declining birth-rate, the population in Japan is falling day by day. 
That is why in the contemporary Japanese corporate culture the employees of the company are given more priority than the family members. As a result, the current demographic condition of Japan has played a key role in making kinship's relationship less important in Japanese contemporary corporate culture.

\section{Conclusion}

In traditional Japanese society, the main goal of the members of the IE was to take care of their elders and maintain the continuity of family harmony in honour of ancestors and families. It was even seen that the members of the family were sacrificing their pleasures to protect the Honor of their family and were doing their utmost to protect the reputation of the family. $I E$ is more powerful than the Japanese sense of self, particularly in the rural society.

In contemporary Japan, a slightly different cultural attitude is being observed where large families have broken into smaller ones. The interests of the individual appear to be greater than the long-term interests of the family, which is termed as 'IE goroshi' (家一殺 $L$ ) (killing of the $I E$ ) by Kunio Yanagita. The rural families now seem to be disappeared due to the changing nature of the family in Japan having four to five generations.

Although Japan's IE system has been pushed by modernity, it has not been completely abolished. Despite changes in the family system and kinship in Japan during World War II, traditional kinship patterns still influence family life in many ways. Men are still considered as the head of the family and the eldest child of the family takes over the authority of the family. In the $I E$ system, just as the head of the household ensures the well-being of all family members and takes care of them, so in corporate culture, the head of the company assumes responsibility for his employees and their families.

However, this kinship relationship in Japan is very different from Bangladesh and other Asian countries. Usually, in Bangladesh or other South Asian countries, an individual's wealth is distributed among his relatives. In all these countries kinship is given the most priorities. People even wait when he will meet his relatives and run to their kin on any occasion. The same culture can be seen in regions like America and Europe. But the difference is only in the case of Japan.

Finally, it could be concluded in this way that Japan was and is a hierarchical society, though the constitution represents the society where everyone is equal, 
but the reality is far away from that. They always promote collectiveness rather than individuality and to be worked and honoured as a frame, maintaining this hierarchy is inevitable for them and they are aware of that. The Kinship knot inside the family system has been loosen its tie in present days but the sense of oneness is still intact among them in broader aspects and that is the value and interiority of Japan which is praiseworthy for sure.

\section{References}

Ashley, C. (2020). Kinship: Definition in the study of Sociology. Thought Co. Retrieved from https://www.thoughtco.com/kinship-3026370 (Accessed on July 5, 2020).

Befu, H. (1963). Patrilineal Descent and Personal Kindred in Japan. American Anthropologist, 65(6), 1328-1341. https://anthrosource.onlinelibrary.wiley.com/doi/abs/10.1525/aa.1963.65.6. 02a00070 (Accessed on July 6, 2020).

Befu, H. (1971). Japan: An Anthropological Introduction. San Francisco: Chandler.

Benedict, R. (1946). Chrysanthemum and the Sword. America, Houghton Mifflin.

Culture of Japan-history, people, traditions, women, beliefs, food, family, social, marriage. (n.d). Retrieved August 2, 2020, from https://www.everyculture.com/Ja-Ma/Japan.html

Dore, R. (1958). City Life in Japan: A Study of a Tokyo Ward. Berkeley: University of California Press.

Faridi, R. (2019, January 28). Kinship: A System of Social Organization. https:// rashidfaridi.com/2019/01/28/kinship-a-system-of-social-organization/ (Accessed on July 22, 2020).

Goldfarb, K.E. (2016). Family at the Margins: State, Welfare and Well-being in Japan. Japanese Studies, 36(2), 151-154. https://www.tandfonline.com/doi/full/10.1080/10371397.2016. 1209730 (Accessed on July 6, 2020).

Gouge, K. L. (2017). The Ties That Bind: Kinship, Inheritance, and the Environment in Medieval Japan, (Unpublished PhD Thesis), Department of History, University of Michigan, USA. https://deepblue.lib.umich.edu/bitstream/handle/2027.42/138481/kgouge_1.pdf?sequence=1\&i sAllowed=y (Accessed on July 8, 2020)

Hareven, T. K. (1991). The History of the Family and the Complexity of Social Change. The American Historical Review, 96(1), 95-124. http://www.jstor.com/stable/2164019 (Accessed on July 6, 2020).

Hidasi, J. (2014). Kinship Terminology from a Cultural Perspective: Japanese versus? Hungarian. https://gender.jp/wp/wp-content/uploads/2019/02/NGG_journal_14_hidasi.pdf (Accessed on July 6,2020 ).

Japan is fighting back against loneliness among the elderly. (2019). Retrieved August 5, 2020, from https://apolitical.co/en/solution_article/japan-is-fighting-back-against-loneliness-among-the-elderly

Japanese-Kinship. (n.d). Retrieved July 27, 2020, from https://www.everyculture.com/EastSoutheast-Asia/Japanese-Kinship.html

Kato, A. (2013). The Japanese Family System: Change, Continuity, and Regionality over the Twentieth century. Max Planck Institute for Demographic Research. https://www.demogr. mpg.de/papers/working/wp-2013-004.pdf\#search=\%22the\%20japanese $\% 20$ family $\%$ 20system $\% 20 \% 20$ change $\% 20 \% 20$ continuity $\% 20 \% 20$ and $\% 20$ regionality $\% 20$ over $\% 20$ the $\% 20$ t wentieth\%20century\%22 (Accessed on July 7, 2020) 
Koyama, T. (1962). Gendai Kazoku no Kenyu [Study of Modern Family]. Tokyo: Kobundo.

Krakow, P. D. (2014). Japanese kinship terms of address and reference-selected approaches. https://core.ac.uk/reader/169420790 (Accessed on June 23, 2020).

Kuwayama, T. (2001). The Discourse of Ie (Family) in Japan's Cultural Identity and Nationalism: A Critique. Japanese Society of Cultural Anthropology, 2. Retrieved from https://www.researchgate.net/publication/327106327_The_Discourse_of_Ie_Family_in_Japan \%27s_Cultural_Identity_and_Nationalism_A_Critique (Accessed on July 18, 2020).

Maeda, H. M. (2010). Name Changes and Kinship Ideology in Japan. Taiwan Journal of Anthropology, 8(1), 77-91.

Morikawa, H. (1992). The Rise and Fall of Family Enterprise Groups in Japan. Tokyo: University of Tokyo Press.

Nakane, C. (1967). Kinship and Economic Organization in Rural Japan. Routledge.

Nakane, C. (1970). Japanese Society. University of California Press.

Ravina, M. J. (2017, May 8). Japanese Cultural and Family Life in Japan. https://www.thegreatcoursesdaily.com/japanese-family-life-a-historical-perspective/ (Accessed on July 15, 2020).

Sakata, S. (2013). Historical Origin of the Japanese Ie System. Chuo University Press. Retrieved from http://global.chuo-u.ac.jp/english/features/2014/03/4411/ (Accessed on July 2, 2020).

Sara, Y. (2018, April 6). 5 major differences between Japanese and American workplace. Business Insider. Retrieved from https://www.businessinsider.com/differences-between-japanese-andamerican-work-culture-2018-3 (Accessed on July 18, 2020).

Schwimmer, B. (2001). Basic Kinship Classification Systems. Retrieved from the University of Manitoba Website: https://www.umanitoba.ca/faculties/arts/anthropology/tutor/kinterms/ termsys.html (Accessed on July 6, 2020).

Suzuki, T. (1978). Words in Context. A Japanese perspective on language and culture. Tokyo: Ko dansha International.

The company in Japanese business culture. (n.d.). Retrieved July 15, 2020, from https://www.venturejapan.com/doing-business-in-japan/secrets-of-japanese-businessculture/the-company-in-japanese-business-culture/

Types of Kinship and Descent Systems; Its Advantages and Disadvantages. (2015). Retrieved July 18, 2020, from https://informationparlour.com/article-culture-tradition-types-kinship-anddescent-systems-its-advantages-and-disadvantages

Vogel, E. (1963). Japan's New Middle Class. Berkeley: University of California Press.

Yamane, T., \& Nonoyama, H. (1967). Isolation of the Nuclear Family and Kinship Organization in Japan: A Hypothetical Approach to the Relationships between the Family and Society. Journal of Marriage and Family, 29(4), 783-796. https://www.jstor.org/stable/349233?seq= 1\#metadata_info_tab_contents (Accessed on July 6, 2020).

Yanagita, K. (1997). Time and Agricultural Policy. Tokyo: Chikuma Shobo. 